\title{
Recent trends in COPD prevalence in \\ Spain: a repeated cross-sectional survey
} 1997-2007

\author{
J.B. Soriano*, J. Ancochea ${ }^{\#}$, M. Miravitlles ${ }^{\uparrow,+}$, F. García-Río ${ }^{\S}$, E. Duran-Tauleria ${ }^{f, * *}$, \\ L. Muñoz $^{\# \#}$, C.A. Jiménez-Ruiz ${ }^{\uparrow}$, J.F. Masa ${ }^{\uparrow,++}$, J.L. Viejo ${ }^{\S \S}$, C. Villasante ${ }^{\S}$, \\ L. Fernández-Fau ${ }^{\#}$, G. Sánchez ${ }^{f f}$ and V. Sobradillo-Peña***
}

ABSTRACT: We aimed to describe changes in the prevalence of chronic obstructive pulmonary disease (COPD) in Spain by means of a repeated cross-sectional design comparing two population-based studies conducted 10 yrs apart.

We compared participants from IBERPOC (Estudio epidemiológico de EPOC en España) $(n=4,030)$, conducted in 1997, with those of EPI-SCAN (Epidemiologic Study of COPD in Spain) $(n=3,802)$, conducted in 2007. Poorly reversible airflow obstruction compatible with COPD was defined according to the old European Respiratory Society definitions.

COPD prevalence in the population between 40 to $69 \mathrm{yrs}$ of age dropped from $9.1 \%$ (95\% $\mathrm{Cl} 8.1-$ $10.2 \%$ ) in 1997 to $4.5 \%$ (95\% $\mathrm{Cl} 2.4-6.6 \%)$, a $50.4 \%$ decline. The distribution of COPD prevalence by severity also changed from $38.3 \%$ mild, $39.7 \%$ moderate and $22.0 \%$ severe in 1997 , to $85.6 \%$ mild, $13.0 \%$ moderate and $1.4 \%$ severe in 2007, and in the $40-69$ yr EPI-SCAN sub-sample to $84.3 \%$ mild, $15.0 \%$ moderate and $0.7 \%$ severe. Overall, underdiagnosis was reduced from $78 \%$ to $73 \%$ (not a significant difference) and undertreatment from $81 \%$ to $54 \%(p<0.05)$ within this 10 -yr frame.

The finding of a substantial reduction in the prevalence of COPD in Spain is unexpected, as were the observed changes in the severity distribution, and highlights the difficulties in comparisons between repeated cross-sectional surveys of spirometry in the population.

KEYWORDS: Chronic obstructive pulmonary disease, EPI-SCAN, IBERPOC, prevalence, Spain

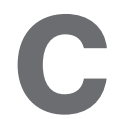

hronic obstructive pulmonary disease (COPD) is a leading but under-recognised cause of morbidity and mortality worldwide. No other disease that is responsible for comparable burden worldwide is neglected by healthcare providers as much as COPD [1, 2]. The Global Burden of Disease Study from the World Health Organization has been systematically assessing worldwide statistics on mortality and prevalence by disease since 1990 [3], and their 30-yr projections for the global increase in COPD are startling. COPD is projected to move from its current fourth position to third in terms of morbidity, before 2020 [4, 5], mainly owing to the worldwide epidemic of smoking and the changing global demographics, with more people in developed and developing countries living longer and, therefore, being at risk of COPD for longer. Spain is currently experiencing an epidemiological transition. Although smoking prevalence in Spain is decreasing, current estimates still show one of the highest prevalences within Western Europe [6], estimated in 2006 as $30.0 \%$ of the adult population, that is $35.8 \%$ of males and $24.3 \%$ of females [7]. Additionally, the Spanish population is ageing, with a maximal growth expected by 2050 with 53 million inhabitants, and maximal ageing expected by 2060 [7]. Therefore, Spain is a country where the population burden of COPD, and other chronic conditions associated with smoking, are expected to surge in the coming years [8], although the recent reductions in overall smoking warrant a reassessment of these predictions. The available epidemiological data in Spain has been recently reviewed elsewhere [9]. The Estudio epidemiológico de EPOC en España (IBERPOC), a landmark prevalence survey conducted in 1997 [10], reported that $9.1 \%$ of the general Spanish population aged between 40 and 69 yrs had COPD [11]. IBERPOC was the first

\section{AFFILIATIONS}

*Fundación Caubet-CIMERA IIles Balears, Mallorca,

"Hospital La Princesa, Universidad Autónoma de Madrid,

"CIBER Enfermedades Respiratorias,

${ }^{\S}$ Hospital La Paz,

"Unidad Especializada en

Tabaquismo, Comunidad de Madrid, and,

${ }^{f f}$ GlaxoSmithKline, Madrid,

+Fundació Clínic, Institut

d'Investigacions Biomèdiques August

Pi i Sunyer (IDIBAPS), Hospital

Clínic,

fInstitut de Prestacions d'Asistencia

Mèdica al Personal Municipal

(PAMEM), and,

**IMIM-Hospital del Mar, Barcelona,

\#\#Hospital Reina Sofía, Córdoba,

${ }^{++}$Hospital San Pedro de Alcántara,

Cáceres,

${ }^{\S \S}$ Hospital General Yagüe, Burgos, and

***Hospital de Cruces, Bilbao,

Spain.

CORRESPONDENCE

J.B. Soriano

Program of Epidemiology and

Clinical Research, Fundació Caubet-

CIMERA, Carretera Soller km 12

Recinte Hospital Joan March

07110-Bunyola

Illes Balears

Spain

E-mail: jbsoriano@caubet-cimera.es

Received:

Sept 012009

Accepted after revision:

Nov 162009

First published online:

Dec 082009

European Respiratory Journal

Print ISSN 0903-1936

Online ISSN 1399-3003 
large population survey to use post-bronchodilator spirometry to ascertain the prevalence of COPD, and its results on underdiagnoses and undertreatment have also been identified in more recent international surveys elsewhere [12, 13]. The Epidemiologic Study of COPD in Spain (EPI-SCAN) is a new, more recent evaluation of the population distribution of COPD in Spain (fig. 1) [14], and recently reported that, currently, $10.2 \%$ of the general Spanish population aged between 40 and $80 \mathrm{yrs}$ has COPD [15]. However, the comparison of the results of EPISCAN versus IBERPOC is not straightforward. By using the individual, patient-level data of these two studies, we report the changes in COPD prevalence in Spain in 1997 and 2007, and illustrate the difficulty of comparing population estimates of COPD measured by spirometry between different surveys.

\section{METHODS}

We applied a repeated cross-sectional study design to compare the COPD prevalences in Spain in 1997 and 2007. Both studies $[10,14]$ have been described in full elsewhere, and their main similarities and differences are compared in table 1. Briefly, on the one hand IBERPOC was a population survey conducted in seven areas of Spain in 1996-1997. The study randomly identified population participants aged 40-69 yrs, and invited them to perform pre- and post-bronchodilator spirometry. Recommendations for lung function and thresholds to define and stage COPD were determined according to the old European Respiratory Society (ERS) guidelines [20], and COPD was defined by a post-bronchodilator forced expiratory volume in $1 \mathrm{~s}(\mathrm{FEV} 1)$ to forced vital capacity (FVC) ratio $<88 \%$ predicted in males and $<89 \%$ pred in females; similarly, COPD severity was staged as mild if FEV1 was $\geqslant 70 \%$ pred, moderate if FEV1 was $50-69 \%$ pred and severe if FEV1 was $<50 \%$ pred. On the other hand, EPI-SCAN was another population survey conducted in 11 areas of Spain 10 yrs later [14]. The study randomly identified population participants aged $40-80$ yrs, and also invited them to perform pre- and post-bronchodilator

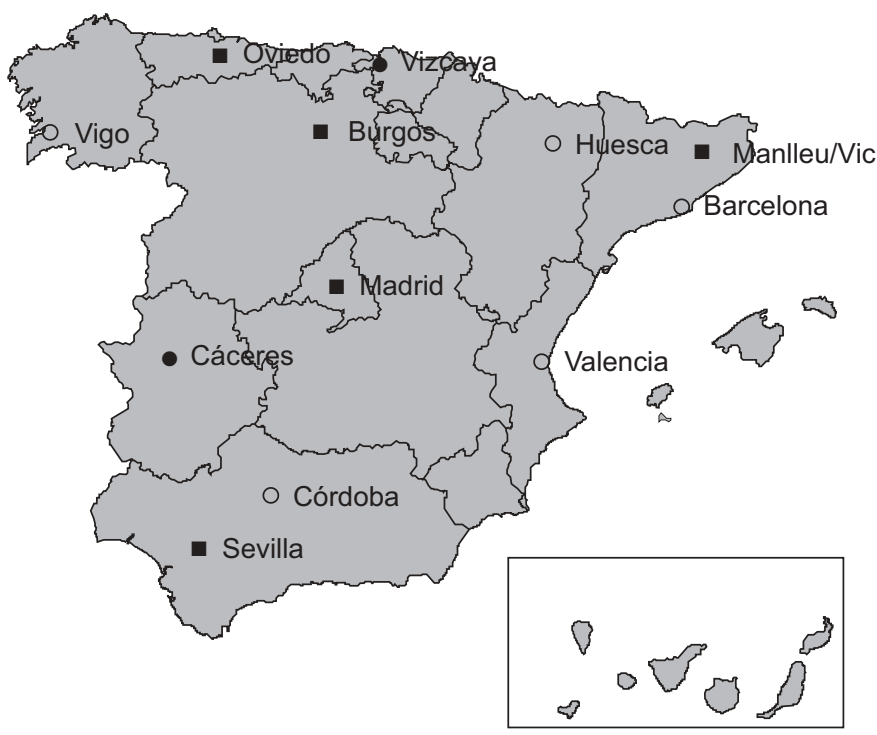

FIGURE 1. Map of Spain displaying the geographical distribution of participating centres for IBERPOC (Estudio epidemiológico de EPOC en España), 1997, and EPI-SCAN (Epidemiologic Study of COPD in Spain), 2007. • : IBERPOC; $O$ : EPI-SCAN; and $\mathbf{\square}$ : both. spirometry. Recommendations for lung function and thresholds to define and stage COPD were according to current Global Initiative for Chronic Obstructive Lung Disease (GOLD) guidelines [21]. So, COPD was defined by a post-bronchodilator ratio FEV1/FVC $<0.70$, and severity was staged as mild if FEV1 was $\geqslant 80 \%$ pred, moderate if FEV1 was $50-80 \%$ pred, severe if FEV1 was $0-50 \%$ pred, and very severe if FEV1 was $<30 \%$ pred.

For the purpose of these analyses, the old ERS recommendations have been used to define and stage COPD [20], and the predicted reference values were re-calculated according to ROCA et al. [18] for the Spanish population. Comparison of IBERPOC results are presented with all, and with the subsample of 40-69yr-old participants in EPI-SCAN. Participants reporting a previous asthma diagnosis were excluded from the analyses, as per the IBERPOC protocol [10].

Questions on previous medical diagnosis compatible with COPD, and on prescribed respiratory treatments, were the same/similar in both surveys and they were used to determine changes in underdiagnosis and undertreatment.

Both studies received approval by an ethics committee and all subjects provided written informed consent to participate in the studies $[10,14]$.

\section{Statistical analysis}

A descriptive and comparative analysis of sociodemographic and clinical variables between both study samples has been performed. The EPI-SCAN sample has been described including all subjects and defining the same age group (40-69 yrs) as the IBERPOC study. Data is presented as mean $\pm S D$ for continuous variables, or percentage for qualitative variables, as appropriate. Prevalences are presented as percentages and their 95\% confidence interval by sex, age and area. In order to compare the prevalences between studies, data from the EPI-SCAN study have been adjusted by age and sex using indirect standardisation. Differences within groups were compared with Chi-squared tests for categorical variables and unpaired t-tests for continuous variables. A p-value $<0.05$ was considered statistically significant.

\section{RESULTS}

A flowchart of participation according to IBERPOC is presented in figure 2 . The demographic and clinical characteristics of both surveys are summarised in table 2. The characteristics of the subgroup of EPI-SCAN participants of age 40-69 yrs are presented as an additional column in table 2. When comparing this EPI-SCAN subgroup with the IBERPOC participants, they had no significant differences in the age and sex distribution. But, 2007 participants were taller $(161.8 \mathrm{~cm}$ versus $164.7 \mathrm{~cm}$ ) but with an identical mean body mass index of $27 \mathrm{~kg} \cdot \mathrm{m}^{-2}$, were more often current or ex-smokers, and more often had a higher degree of education (all $\mathrm{p}<0.05$ ). The average smoking history in IBERPOC participants was $27.8 \pm 22.9$, while in EPI-SCAN participants it was $26.0 \pm 21.5$ pack-yrs; that is, very similar, although IBERPOC included older participants aged 70-79 yrs. Whenever those aged 70 yrs or older were excluded, smoking history went down to $24.4 \pm 19.9$ pack-yrs $(\mathrm{p}<0.001 ;$ table 2$)$. In the IBERPOC study, the average distribution of pack-yrs by centre ranged from the highest in Caceres $(34.1 \pm 25.7)$ to the lowest in Manlleu $(25.0 \pm 21.2$ pack-yrs), 
TABLE 1 Comparison of study designs, definitions and thresholds originally used in the 1997 and 2007 surveys

IBERPOC, $1997[11]$

EPI-SCAN, 2007 [14]

\begin{tabular}{|c|c|}
\hline Participating areas & $\begin{array}{l}\text { Burgos, Cáceres, Madrid, Manlleu, Oviedo, Sevilla and } \\
\text { Vizcaya }\end{array}$ \\
\hline Ages & $40-69$ yrs \\
\hline Fieldwork & October 1996 to April 1997 \\
\hline Sampling source & Random sample of the general population via census \\
\hline Exclusion criteria & $\begin{array}{l}\text { Individuals reporting asthma, and those unable to conduct } \\
\text { spirometry }\end{array}$ \\
\hline Spirometer & DATOSPIR-200; Sibel S.A., Barcelona, Spain \\
\hline Spirometry guidelines & ATS 1987 update [16] \\
\hline Reference values & RocA et al. [18] \\
\hline COPD definition & $\begin{array}{l}\text { As per old ERS criteria of SIAFAKAS et al. [20]: a post-bronchodilator } \\
\mathrm{FEV}_{1} / \mathrm{FVC}<88 \% \text { pred in males or }<89 \% \text { pred in females; or, in the } \\
\text { few patients in whom bronchodilator testing had not been performed, } \\
\text { an absolute } \mathrm{FEV} 1 / \mathrm{FVC} \text { value }<81 \% \text { and } \mathrm{FEV}_{1}<70 \% \text { pred }\end{array}$ \\
\hline Bronchodilator test & $\begin{array}{l}\text { After two inhalations of salbutamol, and using an inhalation } \\
\text { chamber, a difference between FEV1 or FVC was }>200 \mathrm{~mL} \text { a } \\
\text { nd its relative increase was }>12 \%\end{array}$ \\
\hline COPD staging & $\begin{array}{l}\text { Pre-bronchodilator FEV } 1 \\
\text { Mild: } \geqslant 70 \% \\
\text { Moderate: } 50-69 \% \\
\text { Severe: }<50 \%\end{array}$ \\
\hline
\end{tabular}

Barcelona, Burgos, Córdoba, Huesca, Madrid (two areas)

Oviedo, Sevilla, Valencia, Vic and Vigo

40-80 yrs

May 2006 to July 2007

Random sample of the general population via commercially available database

Inability to conduct spirometry

Master Scope CT; VIASYS Healthcare, Hoechberg, Germany ATS/ERS 2005 [17]

QUANJER et al. [19]

As per current GOLD criteria, RABE et al. [21]

a post-bronchodilator $\mathrm{FEV}_{1} / \mathrm{FVC}<0.70$

As per PeLLEGRINo et al. [22]: after two inhalations of salbutamol, an increase in FEV 1 and/or FVC $\geqslant 12 \%$ of control and $\geqslant 200 \mathrm{~mL}$

Post-bronchodilator FEV 1

Mild: $\geqslant 80 \%$

Moderate: $50-80 \%$

Severe: $30-50 \%$

Very severe: $<30 \%$

COPD: chronic obstructive pulmonary disease; IBERPOC: Estudio epidemiológico de EPOC en España; EPI-SCAN: Epidemiologic Study of COPD in Spain; ATS American Thoracic Society; ERS: European Respiratory Society; GOLD: Global Initiative for Chronic Obstructive Lung Disease; FEV1: forced expiratory volume in 1 s: FVC: forced expiratory volume; \% pred: \% predicted.

while in EPI-SCAN the average distribution by centre ranged from the highest in Vic $(29.2 \pm 24.1)$ to the lowest in Huesca $(22.3 \pm 18.9$ pack-yrs). There were significant differences in all forced spirometry measurements. Mean FEV1 was $87.8 \pm 17.0$ versus $100.8 \pm 17.4 \%$ pred, and FVC was $88.4 \pm 14.6$ versus $98.7 \pm 15.3 \%$ pred, in 1997 versus 2007, respectively. From now onwards, all comparisons with IBERPOC are based on the latter subgroup of EPI-SCAN aged 40-69 yr.

The prevalence of COPD according to the old ERS guidelines dropped from $9.1 \%$ (95\% CI 8.1-10.2\%) in 1997 to $4.5 \%$ (95\% CI 2.4-6.6\%) in 2007, that is, a 50.4\% decline (fig. 3). The distribution of COPD prevalence by severity according to the old ERS criteria changed to a milder population distribution, from $38.3 \%$ mild, $39.7 \%$ moderate and $22.0 \%$ severe in 1997 , to $85.6 \%$ mild, $13.0 \%$ moderate and $1.4 \%$ severe in 2007 , and in the age $40-69$ yrs EPI-SCAN sub-sample to $84.4 \%$ mild, $15.5 \%$ moderate and $2.2 \%$ severe (all $\mathrm{p}<0.05$ ) (fig. 3 ). Interestingly, recalculation of patient-level data, with all combinations of thresholds (old ERS and current GOLD) and restriction to the 40-69 yrs sample or all participants, would have produced a different interpretation of changes in prevalence and severity distribution among both surveys (additional columns in fig. 3).

The decline in COPD prevalence was observed in all age strata and in both sexes, except for a nonsignificant increase from $2.8 \%$ to $4.2 \%$ in COPD prevalence in 50-59-yr-old females $(\mathrm{p}>0.05)$ (fig. 4).
As five areas in IBERPOC were also surveyed in EPI-SCAN (Burgos, Madrid, Oviedo, Sevilla and Vic-Manlleu), changes in local COPD prevalence were explored. It can be seen that in all repeated areas there is a substantial decrease in local COPD prevalence, ranging from an $85 \%$ to a $94 \%$ decrease in Manlleu and Burgos to a $46 \%$ decrease in Oviedo, applicable specially to females in Burgos, where a $94.8 \%$ decrease was observed (table 3). These standardised observed reductions were of $72.4 \%$ in males and $67.9 \%$ in females. Similar significant reductions were observed if the current GOLD recommendations were applied to both surveys (data not shown).

Finally, changes in underdiagnosis, undertreatment and smoking among participants with spirometrically confirmed COPD in both IBERPOC and EPI-SCAN were explored. There was a nonsignificant decrease in underdiagnosis, from $78 \%$ in 1997 to $73 \%$ in 2007 . However, there was a significant decrease in undertreatment, from $81 \%$ in 1997 to $54 \%$ in 2007, which was even greater $(50 \%$ versus $10 \%)$ in those with severe COPD (those with FEV $1<50 \%$ pred). Lung function was indeed more frequently tested in 2007 (16.5\% versus 58.5\%), but more smokers reported never trying to quit smoking $(34.9 \%$ versus $88.7 \%$; both $\mathrm{p}<0.05$ ) (table 4 ).

\section{DISCUSSION}

By repeating a cross-sectional survey 10 yrs later, we can report here a substantial decrease of $50.4 \%$ in COPD prevalence in Spain in the population aged 40-69 yrs between 


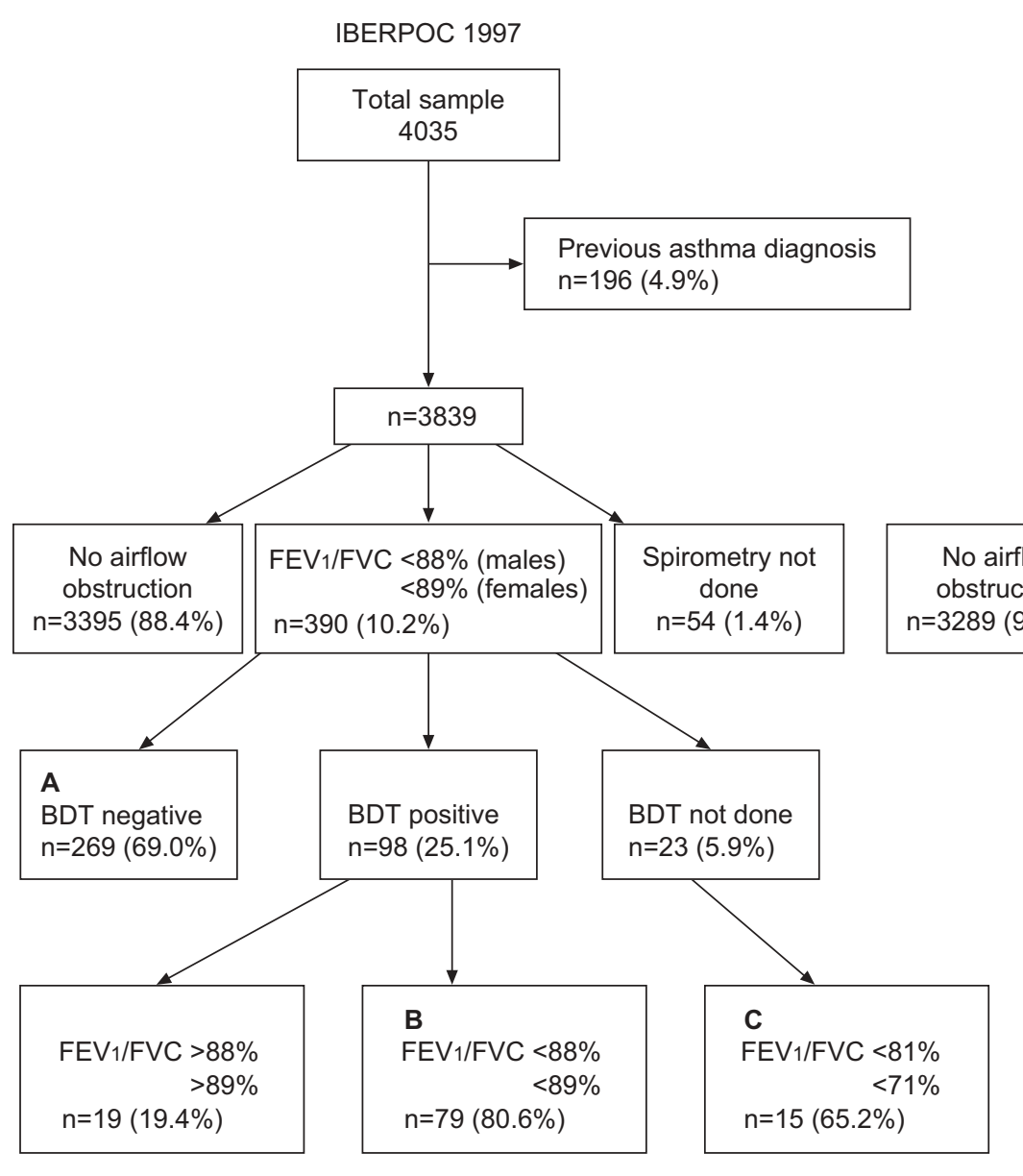

Cases of COPD: $A+B+C=363$ cases
EPI-SCAN 2007

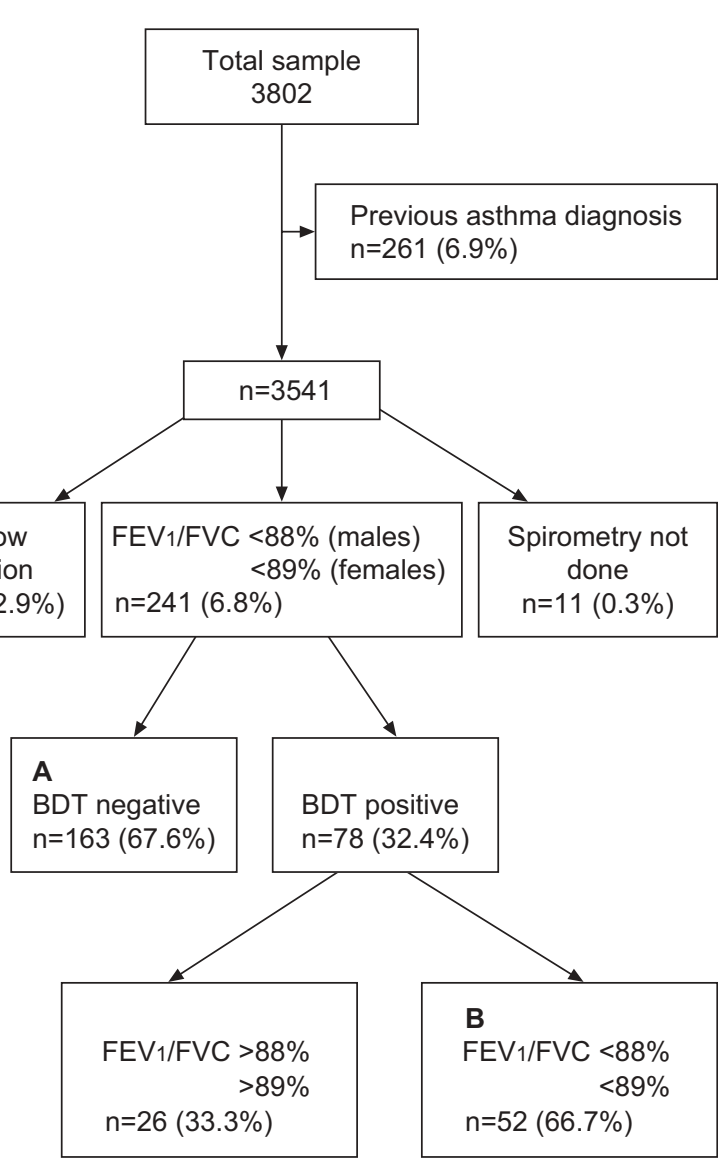

Cases of COPD: $A+B=215$ cases

FIGURE 2. Flowchart of participants in a) IBERPOC (Estudio epidemiológico de EPOC en España) and b) EPI-SCAN (Epidemiologic Study of COPD in Spain). FEV1: forced expiratory volume in $1 \mathrm{~s}$; FVC: forced vital capacity; BDT: bronchodilator test; COPD: chronic obstructive pulmonary disease.

the 10 yrs from 1997 to 2007. This is a surprising, unexpected finding. Due to the cumulative history of exposure to cigarette smoking in Spain, we were actually expecting to find an increase in COPD prevalence in Spain [14], particularly in females [9], rather than the current observed decrease. After careful review of all implemented quality control procedures in IBERPOC and EPI-SCAN, and independent re-calculation of all statistics, our conclusion is sustained. To our knowledge, ours is the first repeated survey of COPD using postbronchodilator spirometry conducted in adults and the elderly from the general population.

\section{Review of previous literature}

Numerous indirect assessments concur that the population burden due to COPD, both worldwide and in Spain, are set to increase in the near future. The global estimates of mortality and morbidity for given diseases made in 1990 were recently updated and confirmed a significant upward trend for COPD [5]. In Europe, the COPD mortality rates range from $<25$ to $>75$ per 100,000 inhabitants within the various European countries with data, and its prevalence ranges from $<2 \%$ to $>10 \%$, also with an expected increase [6]. Both PLATINO (Latin American Project for the Investigation of Obstructive Lung Diseases) and BOLD (Burden of Obstructive Lung
Disease) results identified substantial variability of COPD prevalence within centres. This evidence, together with the instability of results by time reported in here, points to the difficulties of applying current spirometric definitions of COPD [23]. Both the PLATINO and BOLD surveys have identified a significant burden and undetected COPD in most areas, but their cross-sectional nature prevents any conclusion regarding temporal changes regionally or locally $[12,13]$. In asthma, repeated cross-sectional studies conducted in the same areas by the same authors, and using an identical/similar protocol, have reported the transition to the current, expanding asthma epidemic [24-27]. Such evidence is scarce in adults from the population with post-bronchodilator forced spirometry and COPD, with repeated surveys only available from Finland [28] and Sweden [29]. Both countries identified increases in the population burden of COPD $30 \mathrm{yrs}$ after initiation, but did not use post-bronchodilator spirometry, a factor that can modify any final COPD assessment [30].

\section{Limitations}

Apart from the advantages of similar researchers and areas, and closely similar protocols whose differences were taken into account in our analysis, there are some limitations of our research that deserve further discussion. As mentioned above, 
TABLE 2 Demographic and clinical characteristics of participants in 1997 and 2007

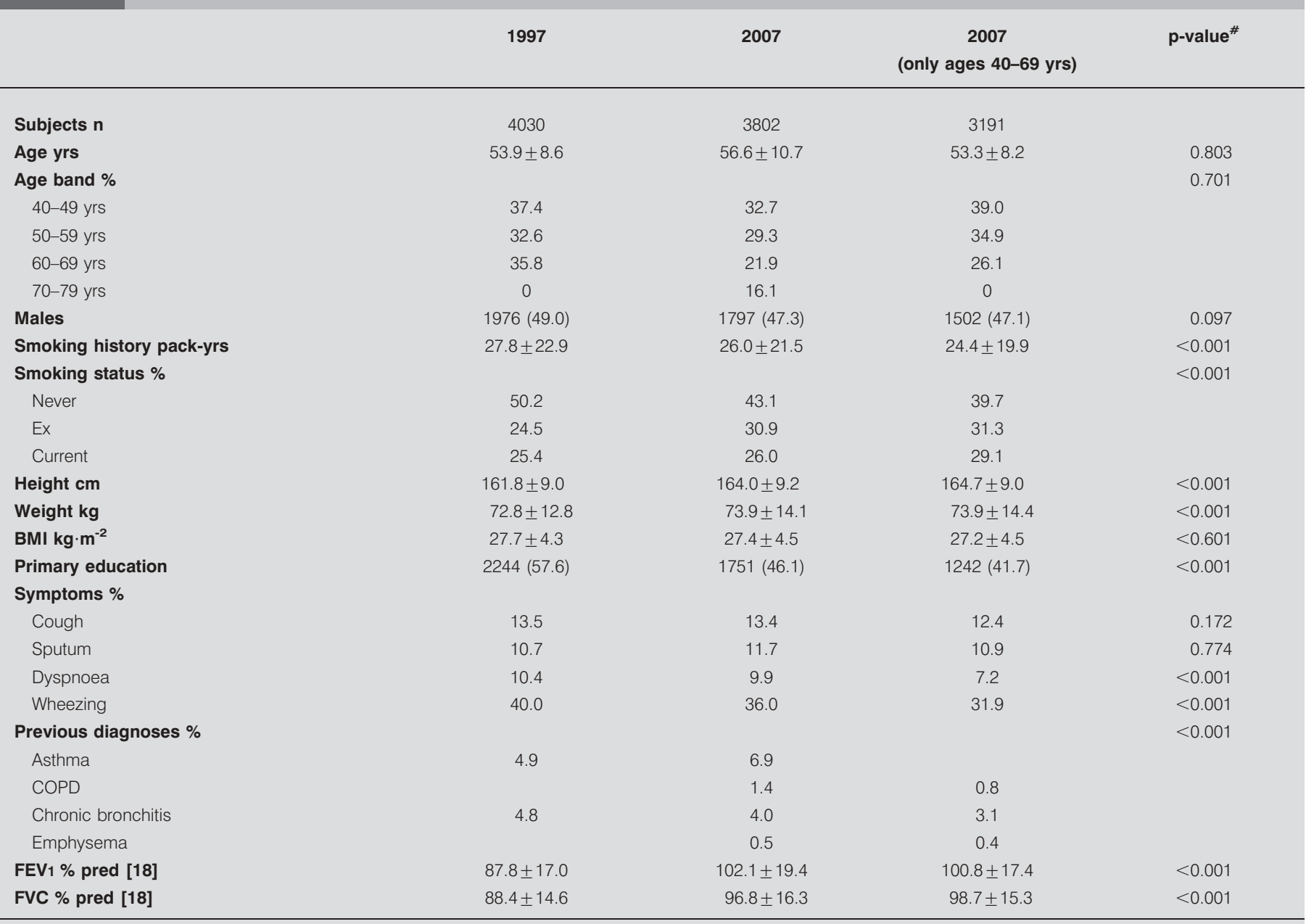

Data are presented as $n(\%)$ or mean \pm SD, unless otherwise stated. BMI: body mass index; COPD: chronic obstructive pulmonary disease; FEV1: forced expiratory volume in $1 \mathrm{~s}$; FVC: forced vital capacity. ${ }^{\#}$ : for 1997 versus those aged 40-69 yrs in 2007.

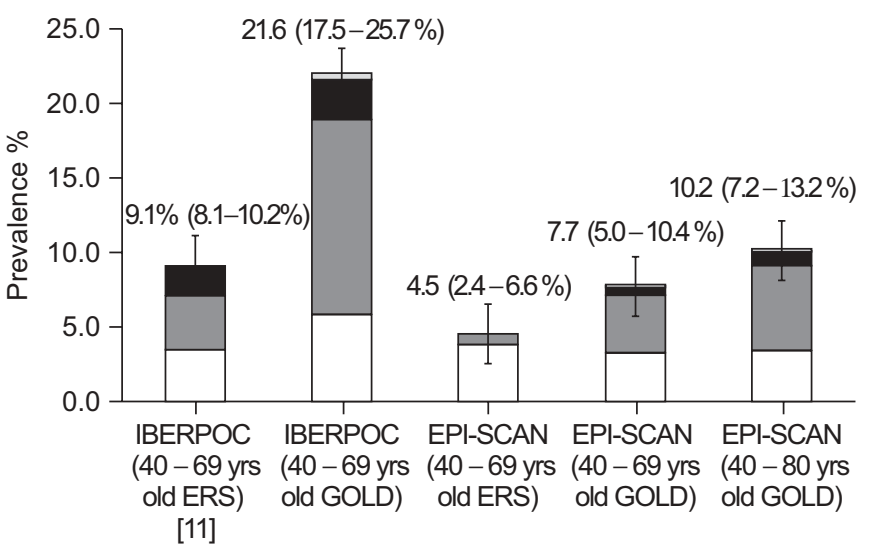

FIGURE 3. Changes in chronic obstructive pulmonary disease (COPD) prevalence and severity from 1997 to 2007. Estimators are presented with 95\% confidence intervals. $\square$ : mild: $\square$ : moderate; $\mathbf{\square}$ : severe; $\mathbf{1}$ : very severe. IBERPOC: Estudio epidemiológico de EPOC en España; ERS: European Respiratory Society; GOLD: Global Initiative for Chronic Obstructive Lung Disease; EPI-SCAN: Epidemiologic Study of COPD in Spain. protocols were not exactly the same and COPD guidelines and forced spirometry recommendations have changed during this relatively short period. We have ensured that re-calculation of individual data from both surveys was conducted consistently, and that similar definitions, thresholds and exclusions were applied. However, the subtle effect of differences in the sampling frame and recruitment, and slight technical changes in spirometry recommendations and/or tools cannot be ruled out to explain, totally or partially, our findings. Without an intention to be cumbersome, a long list of methodological issues are presented as follows. Spirometers used in both surveys differed (table 1). In IBERPOC it was a turbine spirometer, while in EPI-SCAN a pneumotacograph spirometer with high sensitivity was used. It has been reported that turbine spirometers create greater internal resistance to flow, sometimes failing the standards recommended by the American Thoracic Society at high flows [31]. The manufacturer of the pneumotacograph spirometer Datospir-200 reports a maximum resistance of $0.12 \mathrm{kPa} \cdot \mathrm{L}^{-1} \cdot \mathrm{s}^{-1}$ and the turbine MasterScope $0.05 \mathrm{kPa} \cdot \mathrm{L}^{-1} \cdot \mathrm{s}^{-1}$. BuESS et al. [32] suggested that the relationship between the internal resistance of a spirometer 


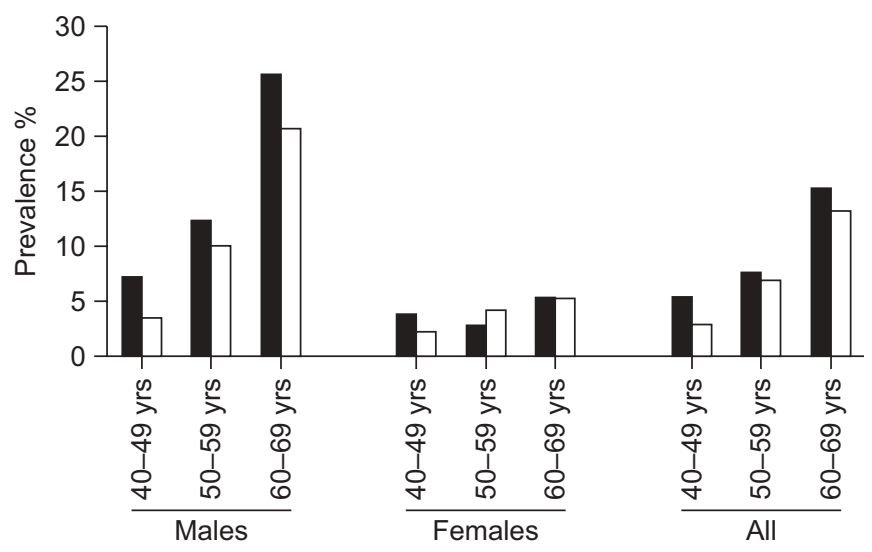

FIGURE 4. Changes in chronic obstructive pulmonary disease (COPD) prevalence from 1997 to 2007, by sex and age. - : IBERPOC (Estudio epidemiológico de EPOC en España); $\square$ : EPI-SCAN (Epidemiologic Study of COPD in Spain).

and the resistance of the respiratory system should be between $5-10 \%$. For a range of resistance of the respiratory system of $0.5-1 \mathrm{kPa} \cdot \mathrm{L}^{-1} \cdot \mathrm{s}^{-1}$ and according to data provided by manufacturers, the pneumotacograph MasterScope meets that criterion, while the turbine spirometer would exceed it by $12-$ $24 \%$. An increase in internal resistance of pneumotacographs can produce an underestimation of expiratory volumes, detecting more COPD, which could have occurred in the IBERPOC study. As this effect occurs early in the expiratory manoeuvre, since most resistance occurs at high flows, it appears that the measure should affect FEV1 more than the FVC, the latter being more dependent on the completion of the manoeuvre. Consequently, an increase of internal resistance of the spirometer could result in an underestimation of the FEV1/FVC ratio. To our knowledge, there is no data in the literature comparing the Datospir 200 spirometer versus pneumotacographs. Accordingly, we re-analysed data considering an underestimation by $6 \%$ in the FEV1/FVC due to turbine spirometers, producing a prevalence of COPD according to the old ERS criteria in EPI-SCAN of 10.6\% $(95 \%$ CI $9.6-11.5 \%$ ). In the subgroup of individuals aged $40-69 \mathrm{yrs}$, the estimated prevalence of COPD would then be $9.2 \%(95 \%$ CI $8.2-10.2 \%)$, virtually identical to the $9.1 \%$ reported in the IBERPOC study.

A final limitation to consider is the often arbitrary decision when applying reference equations to estimate predicted lung function. We used those defined by RocA et al. [18], as they are preferred to other available equations for being locally produced and therefore more representative, as recommended elsewhere [21]. However, they were obtained in the mid 1980s. As the Spanish population has grown taller and leaner 21 yrs later, their ongoing validity might be debatable, as their application produced an observed mean FEV1 of $87.8 \%$ pred in 1997 and $100.8 \%$ in 2007 (table 1). Therefore, additional caution in the interpretation of changes in results of any spirometric survey should be granted when repeated, as changing lung reference equations might have a major effect. Only a reanalysis of raw data, as applied here, would identify this problem.

\begin{tabular}{|c|c|c|c|c|}
\hline \multirow[t]{2}{*}{ TABLE 3} & \multicolumn{4}{|c|}{$\begin{array}{l}\text { Changes between } 1997 \text { and } 2007 \text { chronic } \\
\text { obstructive pulmonary disease prevalence in the } \\
\text { five repeater areas, total and by sex, crude and } \\
\text { adjusted by indirect standardisation, in 40-69-yr- } \\
\text { olds according to old European Respiratory } \\
\text { Society thresholds [20] }\end{array}$} \\
\hline & 1997 & 2007 & $\begin{array}{c}2007 \\
\text { standardised }\end{array}$ & $\begin{array}{l}\% \text { change } 1997 \text { to } \\
2007 \text { standardised }\end{array}$ \\
\hline \multicolumn{5}{|l|}{ All } \\
\hline Burgos & 11.9 & 1.9 & 1.9 & -84.0 \\
\hline Madrid & 11.8 & 6.0 & 6.1 & -48.3 \\
\hline Oviedo & 9.5 & 5.4 & 5.1 & -46.3 \\
\hline Sevilla & 8.7 & 3.2 & 2.1 & -75.9 \\
\hline Vic-Manlleu & 22.3 & 3.4 & 3.3 & -85.4 \\
\hline \multicolumn{5}{|l|}{ Males } \\
\hline Burgos & 16.5 & 3.3 & 3.5 & -78.8 \\
\hline Madrid & 20.2 & 8.8 & 9.1 & -55.0 \\
\hline Oviedo & 12.1 & 5.1 & 4.6 & -62.0 \\
\hline Sevilla & 11.5 & 5.8 & 3.7 & -67.8 \\
\hline Vic-Manlleu & 28.8 & 4.0 & 3.9 & -86.5 \\
\hline \multicolumn{5}{|l|}{ Females } \\
\hline Burgos & 7.7 & 0.5 & 0.4 & -94.8 \\
\hline Madrid & 4.1 & 3.7 & 3.6 & -12.2 \\
\hline Oviedo & 7.0 & 5.7 & 5.7 & -18.6 \\
\hline Sevilla & 5.6 & 0.9 & 0.7 & -87.5 \\
\hline Vic-Manlleu & 17.0 & 2.7 & 2.8 & -83.5 \\
\hline
\end{tabular}

The use of lower limit of normal (LLN) to define and stage COPD has been postulated as more advantageous than previous and current recommendations, all based on fixed spirometry ratios [33], which may misdiagnose large segments of the very young and the very old $[34,35]$. In a way, the old ERS definition of COPD used in this study, with its variable post-bronchodilator ratio FEV1/FVC percentage lower than a

\begin{tabular}{|c|c|c|c|}
\hline \multirow[t]{2}{*}{ TABLE 4} & \multicolumn{3}{|c|}{$\begin{array}{l}\text { Changes in determinants and attitudes towards } \\
\text { chronic obstructive pulmonary disease (COPD) } \\
\text { and smoking among participants with } \\
\text { spirometrically confirmed COPD in } 1997 \text { and } \\
2007\end{array}$} \\
\hline & & 1997 & 2007 \\
\hline \multicolumn{2}{|c|}{ Underdiagnosis \% } & 78 & 73 \\
\hline \multicolumn{2}{|c|}{ Undertreatment \% } & $81^{*}$ & 54 \\
\hline \multicolumn{2}{|c|}{ Undertreatment in severe COPD \% } & $50 *$ & 10 \\
\hline \multicolumn{2}{|c|}{ Lung function ever measured previously \% } & $16.5^{\star}$ & 58.5 \\
\hline \multicolumn{4}{|c|}{ Have you ever tried to quit smoking? $\%$} \\
\hline \multicolumn{2}{|l|}{ Never } & $34.9 *$ & 88.7 \\
\hline \multicolumn{2}{|l|}{ Yes } & 65.1 & 11.3 \\
\hline \multicolumn{2}{|c|}{$1-3$ times } & 43.6 & \\
\hline \multicolumn{2}{|c|}{4 times or more } & 21.5 & \\
\hline \multicolumn{2}{|c|}{ No answer } & 4.0 & \\
\hline
\end{tabular}


predicted value by sex, is already a type of LLN. However, to compare LLN to current thresholds was not the aim of our study, and we doubt our data will help to settle this controversy.

Should the findings be true, some factors can be considered that might explain, albeit partly, this unexpected finding of a COPD prevalence decrease. Changes in tobacco consumption in Spain have been well documented. The prevalence of smokers in adults in Spain significantly dropped in males from $39.9 \%$ in 1999 to $32.1 \%$ in 2007 , while only from $24.6 \%$ to $22.1 \%$ in females in the same period [36]. The actual point prevalence of smoking at the time of conducting the fieldwork of each study, IBERPOC in 1999 and EPI-SCAN in 2007, should not explain the COPD burden, but the cumulative exposure in this population, so it is hard to understand our finding of a $50.4 \%$ decrease in COPD prevalence due to changes in smoking. Although the comparison in pack-years of smoking exposure has to be made with care (table 2), the distribution in smoking exposure among individuals with and without airflow obstruction was $47.2 \pm 28.7$ versus $26.7 \pm 19.4$ pack-yrs in IBERPOC in 1997 [37], a finding that was largely maintained in EPI-SCAN in 2007: $36.5 \pm 18.6$ versus $25.0 \pm 17.2$ pack-yrs (data not shown).

Of interest, the prevalences of respiratory symptoms in both periods (table 2) were similar for cough or sputum, and they are only significant for minor decreases in dyspnoea and wheezing; therefore, it is unlikely they help to explain the magnitude of the differences in spirometric values.

The birth cohort of IBERPOC participants in 1996-1997 suffered the consequences of the Spanish Civil War, from 1936 to 1939. During the 1940s, living conditions in Spain were extremely hard, including starvation and virtually universal infections. As the average year of birth of IBERPOC participants was 1942, the Barker hypothesis on the influence of preconception and early childhood factors on attaining full lung development [38], with a population shift on weight and other factors to influence later spirometry findings [39], and even the effect of tuberculosis [40], common in Spain at that time, might explain a significant unhealthy "cohort effect" in the IBERPOC participants. Conditions gradually improved in subsequent years, so EPI-SCAN participants (1952 being their average year of birth) were actually taller, leaner, and better educated (table 2). A final, relevant factor might be the existence of an outlier centre in the IBERPOC 1997 study; Manlleu participants had a COPD prevalence of $18.0 \%$ (95\% CI 14.8-21.2), which was four-fold higher than the lowest participating area, mostly explained at that time by high occupational exposures in actually nonsmoking females, who had the mildest COPD [41]. 10 yrs later in Vic, another rural village in the outskirts of Barcelona, only $10 \mathrm{~km}$ ( $\sim 6$ miles) from Manlleu, but without any major local industry, we obtained a $4 \%$ COPD prevalence.

Finally, of public health interest, we have to underline from table 4 the nonsignificant drop in COPD underdiagnosis, but the substantial decrease in undertreatment, especially in those with severe COPD. To further reduce underdiagnosis, the implementation and wider use of spirometry screening in all settings, including quality spirometry in primary care [42], pharmacies [43], and elsewhere, require further research and resources [44].

\section{Conclusion}

To conclude, we report a substantial reduction of $50.4 \%$ in the prevalence of COPD in Spain from 1997 to 2007 in subjects aged 40-69 yrs, with also an unexpected shift to a milder severity in the population distribution. These findings remain unexplained, but highlight the difficulty found in comparing population findings of forced spirometry by time and place. Undertreatment (but not underdiagnosis) was significantly reduced during the same period.

\section{SUPPORT STATEMENT}

The IBERPOC study funding was obtained from Boehringer Ingelheim, Spain, SA. The EPI-SCAN study was funded by an unrestricted grant from GlaxoSmithKline Spain.

\section{STATEMENT OF INTEREST}

A statement of interest for G. Sánchez and for the study itself can be found at www.erj.ersjournals.com $/ \mathrm{misc} / \mathrm{statements.dtl}$

\section{ACKNOWLEDGEMENTS}

We sincerely thank the participants, staff and coordinators in both IBERPOC and EPI-SCAN. We thank M. Sarmiento and M. Roset (IMS Health Economics and Outcomes Research, Barcelona, Spain) for the monitoring and data management of this study, and we also thank A. Fueyo (GlaxoSmithKline, Madrid, Spain) for his continuous support. Finally, we acknowledge the blinded European Respiratory Journal reviewers, whose constructive suggestions improved the original submission.

\section{REFERENCES}

1 Curry CW, De AK, Ikeda RM, et al. Health burden and funding at the Centers for Disease Control and Prevention. Am J Prev Med 2006; 30: 269-276.

2 Yach D, Hawkes C, Gould CL, et al. The global burden of chronic diseases: overcoming impediments to prevention and control. JAMA 2004; 291: 2616-2622.

3 Murray CJ, Lopez AD. Alternative projections of mortality and disability by cause 1990-2020: Global Burden of Disease Study. Lancet 1997; 349: 1498-1504.

4 Chapman KR, Mannino DM, Soriano JB, et al. Epidemiology and costs of chronic obstructive pulmonary disease. Eur Respir J 2006; 27: 188-207.

5 Lopez AD, Mathers CD, Ezzati M, et al. Global and regional burden of disease and risk factors, 2001: systematic analysis of population health data. Lancet 2006; 367: 1747-1457.

6 European Respiratory Society/European Lung Foundation. The European Lung White Book: The First Comprehensive Survey on Respiratory Health in Europe. Loddenkemper R, Gibson GJ, Sibille Y, eds. Sheffield, European Respiratory Society Journals, Ltd, 2004.

7 Cifras de población y Censos demográficos. INE 2010. www.ine. es/inebmenu/mnu_cifraspob.htm Last accessed July 2009.

8 Gerez-Valls MD, Velázquez-Valoria I. The health of cities and their citizens (urban development and municipal public health. 2008 SESPAS Report. Gac Sanit 2008; 22: Suppl. 1, 71-78.

9 Soriano JB, Miravitlles M. Datos epidemiologicos en España [Epidemiological data of COPD in Spain]. Arch Bronconeumol 2007; 43: Suppl. 1, 2-9.

10 Comité Científico del Estudio IBERPOC. El proyecto IBERPOC: Un estudio epidemiológico de la EPOC en España [Scientific Committee of the IBERPOC study. The IBERPOC project: an epidemiological study of COPD in Spain]. Arch Bronconeumol 1997; 33: 293-299.

11 Sobradillo-Peña V, Miravitlles M, Gabriel R, et al. Geographic variations in prevalence and underdiagnosis of COPD: results of 
the IBERPOC multicentre epidemiological study. Chest 2000; 118 981-989.

12 Buist AS, McBurnie MA, Vollmer WM, et al. International variation in the prevalence of COPD (the BOLD Study): a population-based prevalence study. Lancet 2007; 370: 741-750.

13 Menezes AM, Perez-Padilla R, Jardim JR, et al. Chronic obstructive pulmonary disease in five Latin American cities (the PLATINO study): a prevalence study. Lancet 2005; 366: 1875-1881.

14 Ancochea J, Badiola C, Duran-Tauleria E, et al. The EPI-SCAN Study: A survey to assess the prevalence of chronic obstructive pulmonary disease in 40 to 80 year old in Spain: protocol summary. Arch Bronconeumol 2009; 45: 41-47.

15 Miravitlles M, Soriano JB, Garcia-Rio R, et al. Prevalence of COPD in Spain: impact of undiagnosed COPD on quality of life and daily life activities. Thorax 2009; 64: 863-868.

16 Standardization of spirometry - 1987 update. Statement of the American Thoracic Society. Am Rev Respir Dis 1987; 136: 1285-1298.

17 Miller MR, Hankinson J, Brusasco V, et al. Standardisation of spirometry. Eur Respir J 2005; 26: 319-338.

18 Roca J, Sanchis J, Agusti-Vidal A, et al. Spirometric reference values from a Mediterranean population. Bull Eur Physiopathol Respir 1986; 22: 217-224.

19 Quanjer PH, Tammeling GJ, Cotes JE, et al. Lung volumes and forced ventilatory flows. Report Working Party Standardization of Lung Function Tests, European Community for Steel and Coal. Official Statement of the European Respiratory Society. Eur Respir J Suppl 1993; 16: 5-40.

20 Siafakas NM, Vermeire P, Pride NB, et al. Optimal assessment and management of chronic obstructive pulmonary disease (COPD). Eur Respir J 1995; 8: 1398-1420.

21 Rabe KF, Hurd S, Anzueto A, et al. Global strategy for the diagnosis, management, and prevention of chronic obstructive pulmonary disease: GOLD executive summary. Am J Respir Crit Care Med 2007; 176: 532-555.

22 Pellegrino R, Viegi G, Brusasco V, et al. Interpretative strategies for lung function tests. Eur Respir J 2005; 26: 948-968.

23 Vollmer WM, Gíslason T, Burney $\mathrm{P}$, et al. Comparison of spirometry criteria for the diagnosis of COPD: results from the BOLD Study. Eur Respir J 2009; 34: 588-597.

24 Burr ML. Epidemiology of childhood asthma. Allerg Immunol (Paris) 1991; 23: 348-350.

25 Pearce N, Sunyer J, Cheng S, et al. Comparison of asthma prevalence in the ISAAC and the ECRHS. ISAAC Steering Committee and the European Community Respiratory Health Survey. International Study of Asthma and Allergies in Childhood. Eur Respir J 2000; 16: 420-426.

26 Burr ML, Wat D, Evans C, et al. Asthma prevalence in 1973, 1988 and 2003. Thorax 2006; 61: 296-299.

27 Björkstén B, Clayton T, Ellwood P, et al. Worldwide time trends for symptoms of rhinitis and conjunctivitis: Phase III of the International
Study of Asthma and Allergies in Childhood. Pediatr Allergy Immunol 2008; 19: 110-124.

28 Pelkonen M, Notkola IL, Nissinen A, et al. Thirty-year cumulative incidence of chronic bronchitis and COPD in relation to 30-year pulmonary function and 40-year mortality: a follow-up in middleaged rural men. Chest 2006; 130: 1129-1137.

29 Lundbäck B, Lindberg A, Lindström M, et al. Not 15 but $50 \%$ of smokers develop COPD? Report from the Obstructive Lung Disease in Northern Sweden Studies. Respir Med 2003; 97: 115-122.

30 Sterk PJ. Let's not forget: the GOLD criteria for COPD are based on post-bronchodilator FEV1. Eur Respir J 2004; 23: 497-498

31 Gunawardena KA, Houston K, Smith AP. Evaluation of the turbine pocket spirometer. Thorax 1987; 42: 689-693.

32 Buess $\mathrm{CH}$, Boutellier U, Koller EA. Pneumotachometers. In Webster JG, ed. Encyclopaedia of Medical Devices and Instrumentation. New York, Wiley, 1988; pp. 2319-2324.

33 Pellegrino R, Brusasco V, Viegi G, et al. Definition of COPD: based on evidence or opinion? Eur Respir I 2008; 31: 681-682.

34 Mannino DM, Buist SA, Vollmer WM. Chronic obstructive pulmonary disease in the older adult: what defines abnormal lung function? Thorax 2007; 62: 237-241.

35 Miller MR, Pedersen OF, Pellegrino R, et al. Debating the definition of airflow obstruction: time to move on? Eur Respir I 2009; 34: 527-528.

36 Spanish National Statistics Institute. www.ine.es Last accessed July 2009.

37 Jiménez-Ruiz C, Miravitlles $M$, Sobradillo $V$, et al. Can cumulative tobacco consumption, FTND score, and carbon monoxide concentration in expired air be predictors of chronic obstructive pulmonary disease? Nicotine Tob Res 2004; 6: 649-653.

38 Barker DJ, Godfrey KM, Fall C, et al. Relation of birth weight and childhood respiratory infection to adult lung function and death from chronic obstructive airways disease. BMJ 1991; 303: 671-675.

39 Roseboom T, de Rooij S, Painter R. The Dutch famine and its longterm consequences for adult health. Early Hum Dev 2006; 82: 485-491.

40 Menezes AM, Hallal PC, Perez-Padilla R, et al. Tuberculosis and airflow obstruction: evidence from the PLATINO study in Latin America. Eur Respir J 2007; 30: 1180-1185.

41 Miravitlles $\mathrm{M}$, Ferrer $\mathrm{M}$, Pont $\mathrm{A}$, et al. Characteristics of a population of COPD patients identified from a population-based study. Focus on previous diagnosis and never smokers. Respir Med 2005; 99: 985-995.

42 Miravitlles M, de la Roza C, Naberan K, et al. Use of spirometry and patterns of prescribing in COPD in primary care. Respir Med 2007; 101: 1753-1760.

43 Castillo D, Guayta R, Giner J, et al. COPD case finding by spirometry in high-risk customers of urban community pharmacies: a pilot-study. Respir Med 2009; 103: 839-845.

44 Soriano JB, Parkes G. Remember elephants and icebergs... "Your lung function should be in here, but it is there!" Eur Respir J 2009; 33: 715-716. 